\title{
AN OPERATION FOR PARTIAL CLOSURE OF AN EPIPHYSIAL PLATE IN CHILDREN, AND ITS EXPERIMENTAL BASIS
}

\author{
A. LANGenskiöld, Helsinki, Finland \\ From the Department of Orthopaedics and Traumatology, University of Helsinki
}

\begin{abstract}
In two cases of partial closure of an epiphysial plate causing angular deformity, one of a finger and one of the lower end of a femur, the deformities were corrected by growth after resection of a small peripheral bone bridge and its replacement with a free transplant of fat. This procedure has a firm basis on experimental work. Thus, when part of a growth plate in the rabbit is destroyed but the formation of a bone bridge uniting epiphysis and metaphysis is prevented, the destroyed part is replaced by regeneration of cartilage from the adjacent parts of the plate. Moreover, it has been proved in rabbits that when a bone bridge is induced and later resected and replaced with fat, recurrence of the bridge can be prevented and subsequent growth may correct the deformity.
\end{abstract}

In 1963 Salter and Harris wrote concerning partial closure of an epiphysial plate that "The resultant deformity is progressive until the end of the child's growing period". In 1967, however, we reported a case in which a bone bridge between the epiphysis and metaphysis of the upper end of the tibia had caused recurvatum by the age of fifteen years. The bridge was resected and replaced have been operated upon in addition to the case reported in 1967. In two of these cases, both reported in this article, an angular deformity was gradually corrected by growth after resection of a small bony bridge at the periphery of a plate and its replacement with fat. In the other ninc patients the following regions were affected: lower end of femur (six), lower end of tibia (two), and

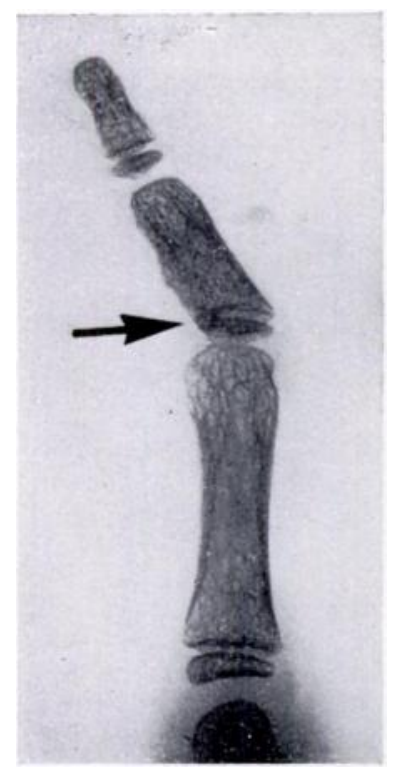

Fig. 1

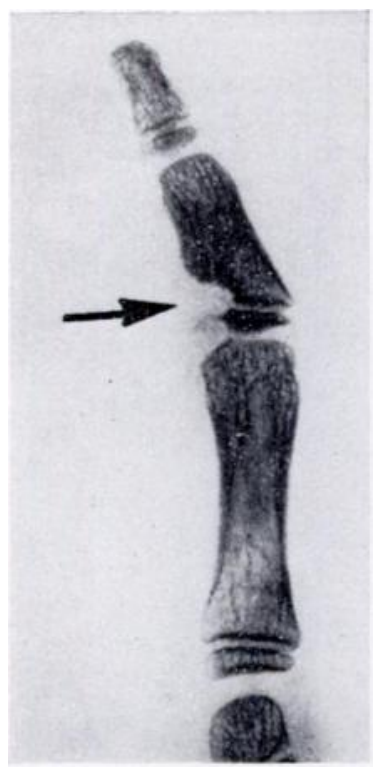

Fig. 2

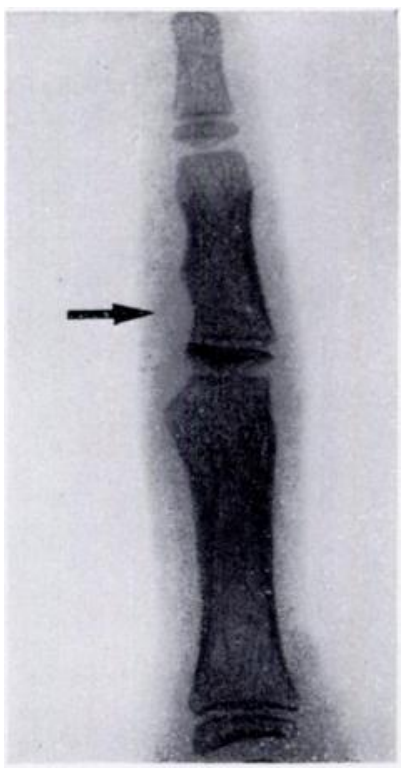

FIG. 3

Case 1. Figure 1-A radiograph taken before operation at 6 years of age. Figure $2-$ One day after operation. Figure 3-Two years after operation.

with a free transplant of fat. It did not reform and the recurvatum diminished by about 10 degrees before growth ceased (Langenskiöld 1967b).

In 1967 there was already an experimental basis for the operation described (Langenskiöld and Edgren 1949; Heikel 1960), and this was further confirmed by Österman (1972). Since Österman's experiments eleven children lower end of fibula (one). In seven of these nine cases there were large bridges with complete or almost complete arrest of growth, but some of the affected bones are still gaining in length after the operation. The scope of the operation in this more severe type of case is not yet clear enough to justify a report. In the last two cases smaller bridges were removed quite recently. 


\section{CASE REPORTS}

Case 1-A girl aged two and a half years sustained a laceration of the fingers of the right hand. The small wounds were sutured and healed uneventfully. Three years later there was radial deviation of about 30 degrees at the proximal interphalangeal joint of the middle finger. The deformity had developed gradually after the injury and was due to the formation of a small bony bridge between epiphysis and metaphysis at the base of the intermediate phalanx (Fig. 1). Re-examination of the radiograph taken on the day of injury revealed a minute fracture of the radial edge of the metaphysis.

Three and a half years after the injury, at the age of six, the bridge of bone was removed and replaced with a transplant of fat. Through a longitudinal incision the radial collateral ligament was exposed and split in the direction of its fibres. Under an operating microscope the joint was opened and the bridge identified. It was removed with a dental burr (Fig. 2). The resulting cavity was filled with a piece of fat, taken from the outer aspect of the thigh and kept in place by the collateral ligament sutured with catgut. The deformity gradually disappeared as growth continued and two years after the operation the finger was completely straight (Fig. 3).

Case 2-A boy aged seven and a half years sustained a blow on the lateral aspect of the left knee, with a small fracture involving the edges of the lower epiphysis and metaphysis of the femur (Fig. 4). Seven years later there was a marked valgus deformity and also slight recurvatum (Fig. 5). The left femur was 1 centimetre shorter than the right. Radiographs showed a bony bridge uniting epiphysis and metaphysis at the site of fracture (Figs. 8 and 10).

When the boy was fourteen and a half years old the bridge of bone was resected and replaced with a free fat transplant. The periphery of the bridge was exposed through a longitudinal lateral incision. There was a shallow depression over the bridge, which was removed under an operating microscope, leaving a round cavity about 3 centimetres in diameter and with an opening to the lateral surface about 2 centimetres across (Fig. 11). A free transplant of fat taken from the gluteal fold filled the cavity completely and just protruded through the opening. The soft tissues were closed with catgut over the transplant. The knee was not immobilised after the operation.

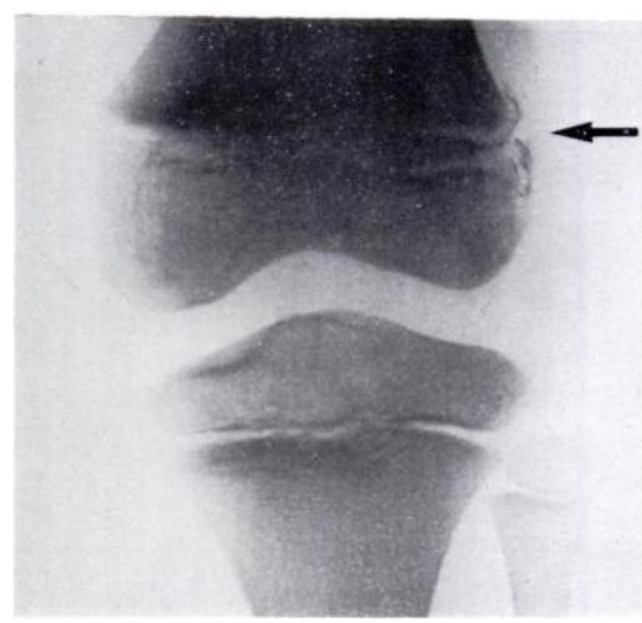

FIG. 4

Case 2-A radiograph of the left knee taken on the day of injury at the age of $7 \frac{1}{2}$ years.

The deformity was gradually corrected by growth (Fig. 6). At the last examination almost two years after operation a slight asymmetry of the lower limbs remained and there was still 1 centimetre of shortening (Figs. 7 and 9). The skeletal age was fifteen years, almost two years less than the calendar age.

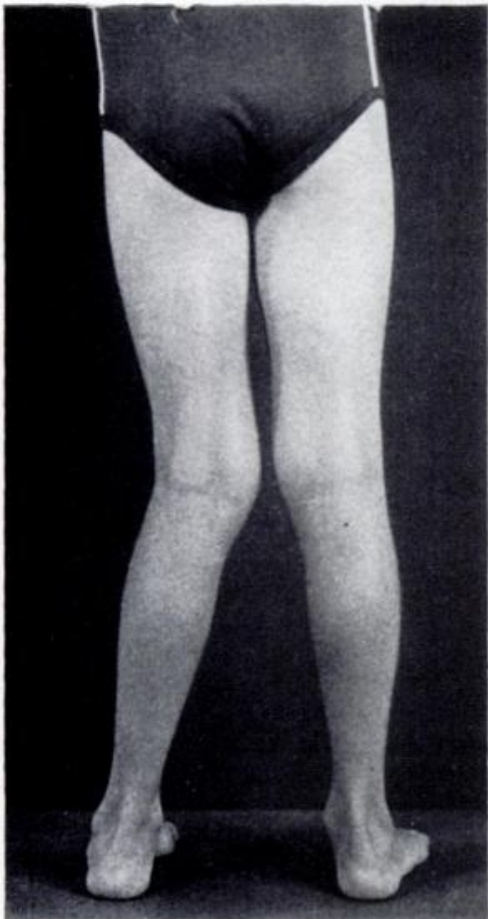

FIG. 5

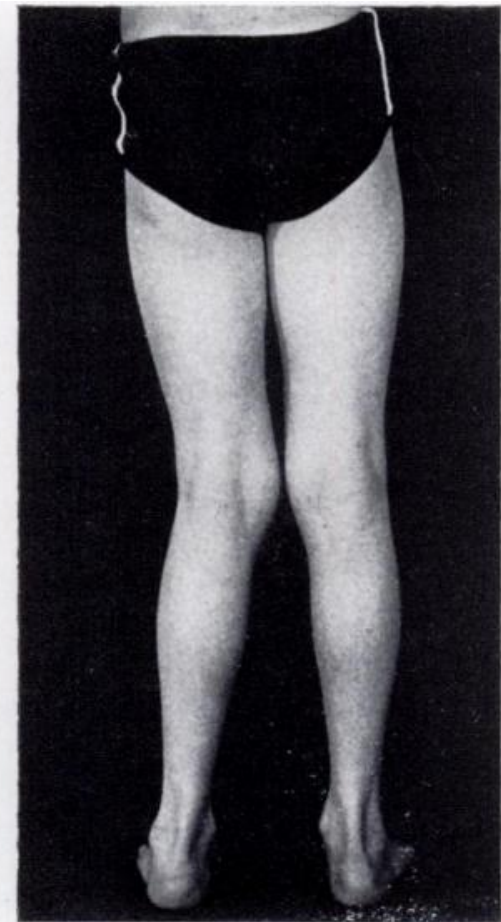

FIG. 6

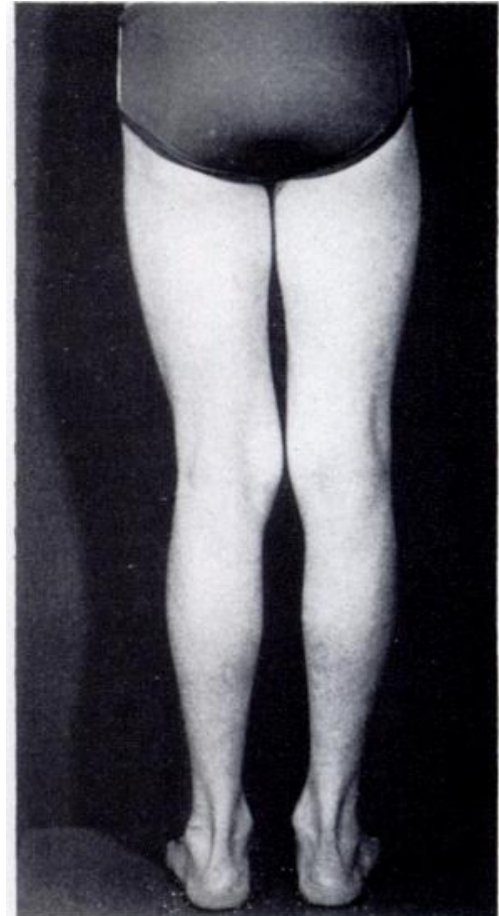

Fig. 7

Case 2. Figure 5-A photograph taken before operation at the age of $14 \frac{1}{2}$ years. Figure $6-$ Nine months after operation. Figure 7-Two years after operation. 


\section{THE OPERATION}

In all children with growth disturbance caused by partial closure of an epiphysial plate and so far selected for the

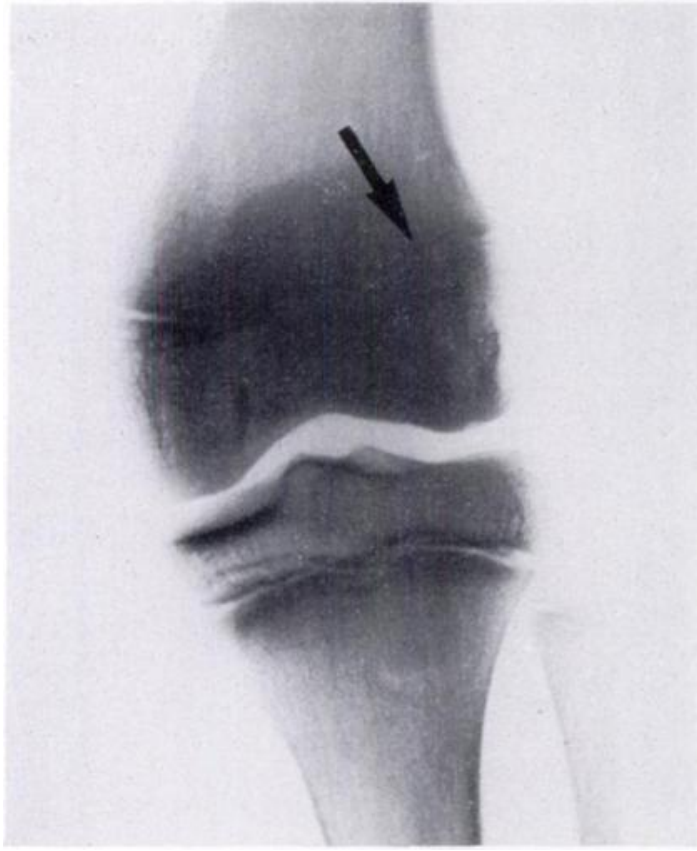

FIG. 8

Case 2. Figure 8-A radiograph taken before operation. Figure 9--A radiograph taken two years after operation.

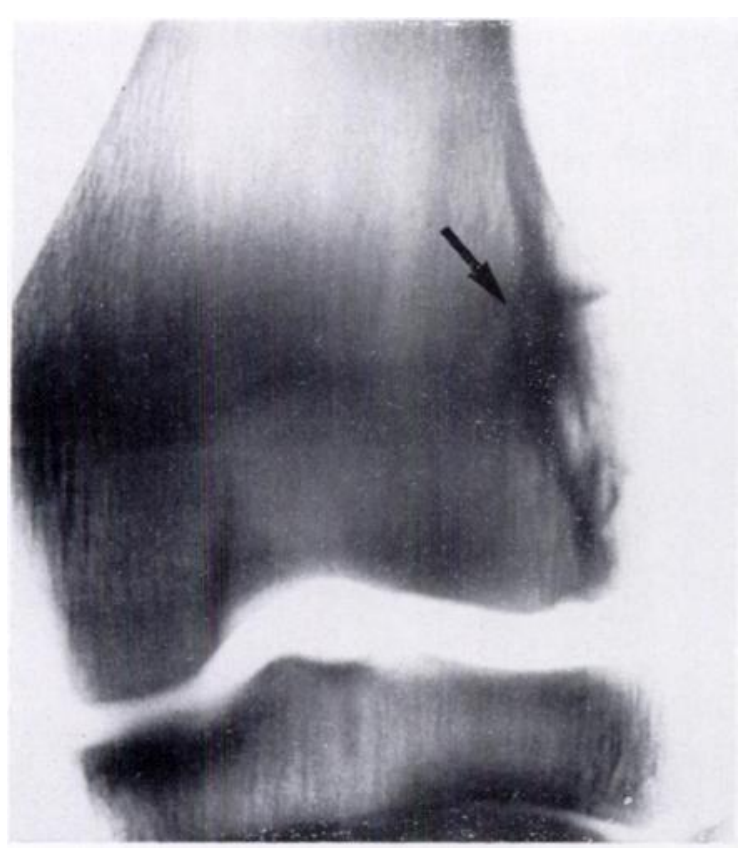

Regardless of the epiphysial plate operated upon, the technical principles are the same. Exact localisation and estimation of the size of the bony bridge by radiography and tomography in at least two directions are

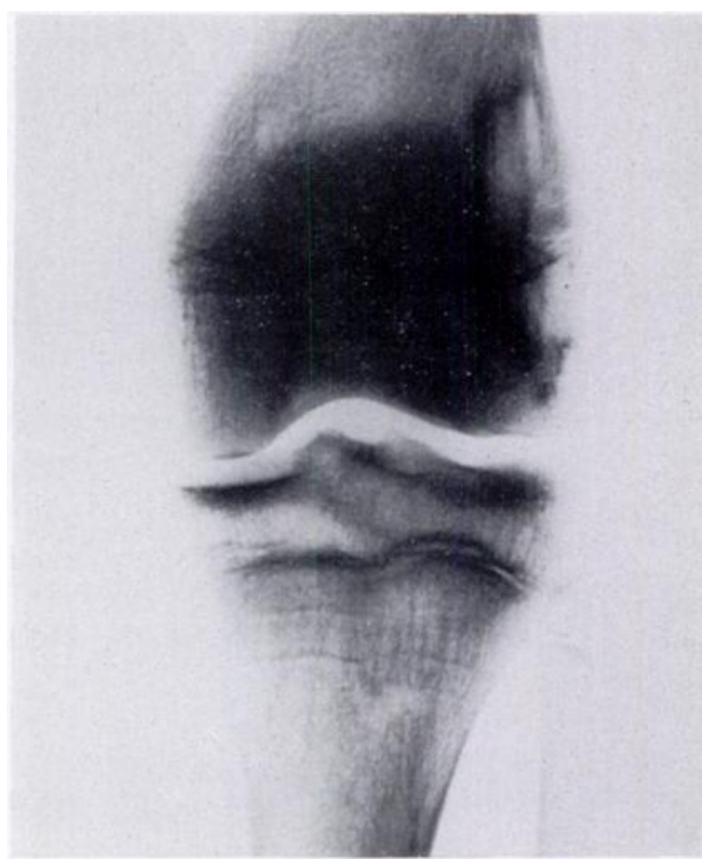

FIG. 9
FIG. 10

Case 2. Figure 10-A tomograph taken before operation. Note the bony bridge uniting epiphysis to metaphysis.

Figure 11-A tomograph taken eleven weeks after operation. Note the cavity in the bone.

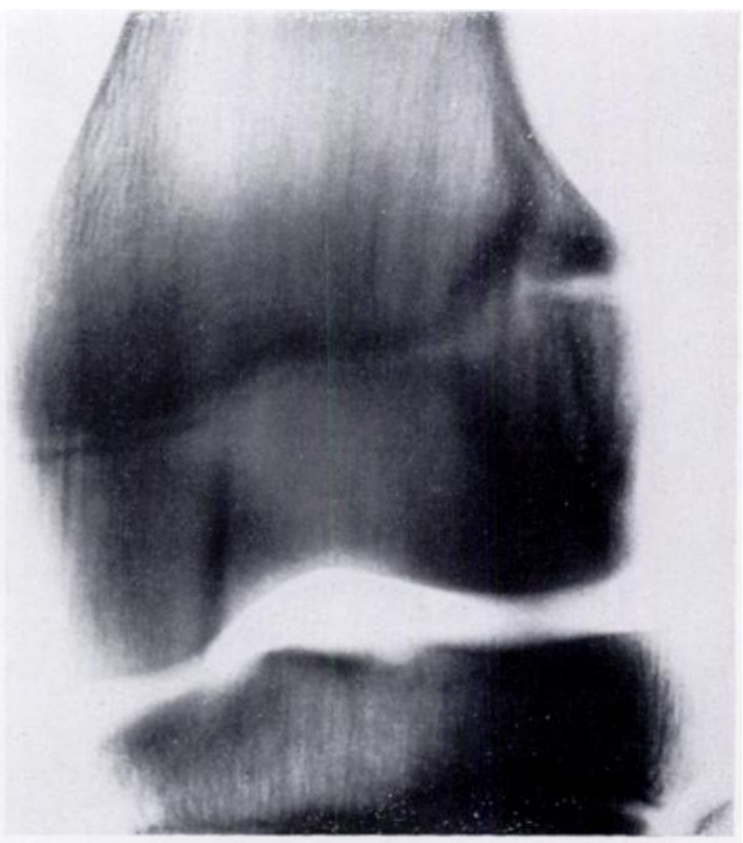

FIG. 11 operation, more than half of the plate has been intact. The bone bridges reached the periphery of the plate and caused either progressive angulation deformity or progressive discrepancy of leg length, or both. 
plate, which is often very thin close to the bridge. The most peripheral part of the bony bridge is defined, the overlying periosteum is removed, and bone is removed until the normal periphery of the epiphysial plate is reached on both sides of the bridge.

The bridge is then removed entirely until cartilaginous plate can be seen around the whole cavity. An operating microscope, or at least a binocular loupe, makes the procedure easier. The amount of metaphysial or epiphysial bone tissue removed does not seem to be important. It is essential that no part of the bridge is left and that normal epiphysial cartilage is not removed unnecessarily.

The tourniquet is then released, and during the time required for haemostasis a piece of fat corresponding to the size of the cavity is taken from subcutaneous tissue elsewhere. The gluteal fold is an area where fat in needed quantity can be taken even in very thin children, best through an incision parallel to the fold.

When bleeding from the cavity in the bone has ceased it is filled with the autogenous fat. If the cavity is irregular the transplant can be divided into several pieces to ensure complete filling. The transplant is kept in place by suturing over it ligament or muscle or subcutaneous tissue. Exact closure of the wound without drainage is recommended.

\section{THE EXPERIMENTAL BASIS OF THE OPERATION}

The technique described is based on experimental observations. The effect of the operation depends mainly on three phenomena: 1) when a portion of the epiphysial plate is destroyed and the formation of bone uniting epiphysis and metaphysis is prevented, the destroyed portion of cartilage is gradually replaced by regeneration from adjacent parts of the plate (Langenskiöld and Edgren 1949; Heikel 1960; Österman 1972); 2) when a bone bridge in a growing bone is resected and replaced with a free fat transplant, recurrence of the bridge is usually prevented (Österman 1972); and 3) when the

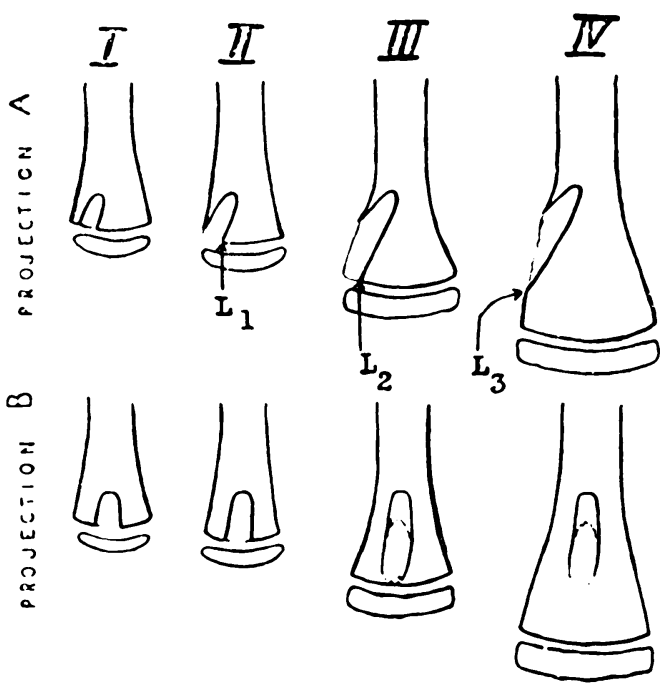

Fig. 12

Line drawings illustrating the development of a cartilaginous focus in dyschondroplasia (Ollier's disease). The stages are shown in two projections at right angles to one another. (Reprinted from Langenskiöld and Edgren (1949) by kind permission.)

deforming effect of partial closure of a growth plate is eliminated, gradual correction of the deformity by growth may take place (Österman 1972).

The initial observations giving an impetus to experiments more than twenty-five years ago were that in Ollier's disease radiographic changes develop in a characteristic manner during growth (Langenskiöld 1947). Those findings suggested that cartilaginous foci arising from an

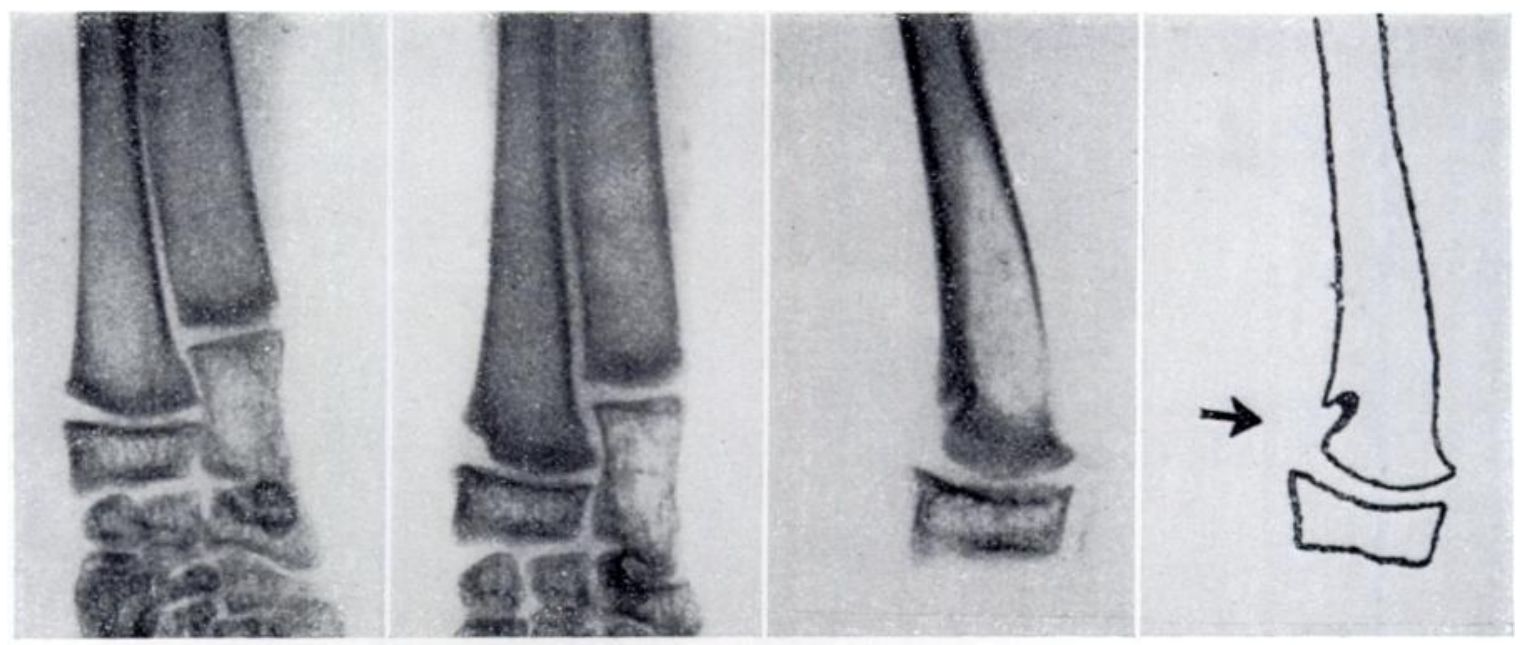

Fig. 13

Radiographs of a rabbit's paw in which the radial part of the distal epiphysial cartilage of the radius was injured by a heavy dose of $\mathrm{x}$-rays. From left to right: sixteen, twenty-two and thirty-two days after irradiation, and an outline-drawing of the last radiograph. Note that the injured portion of the cartilage was left behind as an oblique focus in the metaphysis. (Reprinted from Langenskiöld and Edgren (1949) by kind permission, and enlarged 50 per cent.) 
epiphysial plate of a tubular bone are gradually extruded by growth or regeneration of cartilage in a transverse direction relative to the long axis of the bone (Fig. 12). portions were eliminated from the plate in the same manner as the foci in Ollier's disease (Fig. 13). The injured cartilage did not grow and was slowly replaced
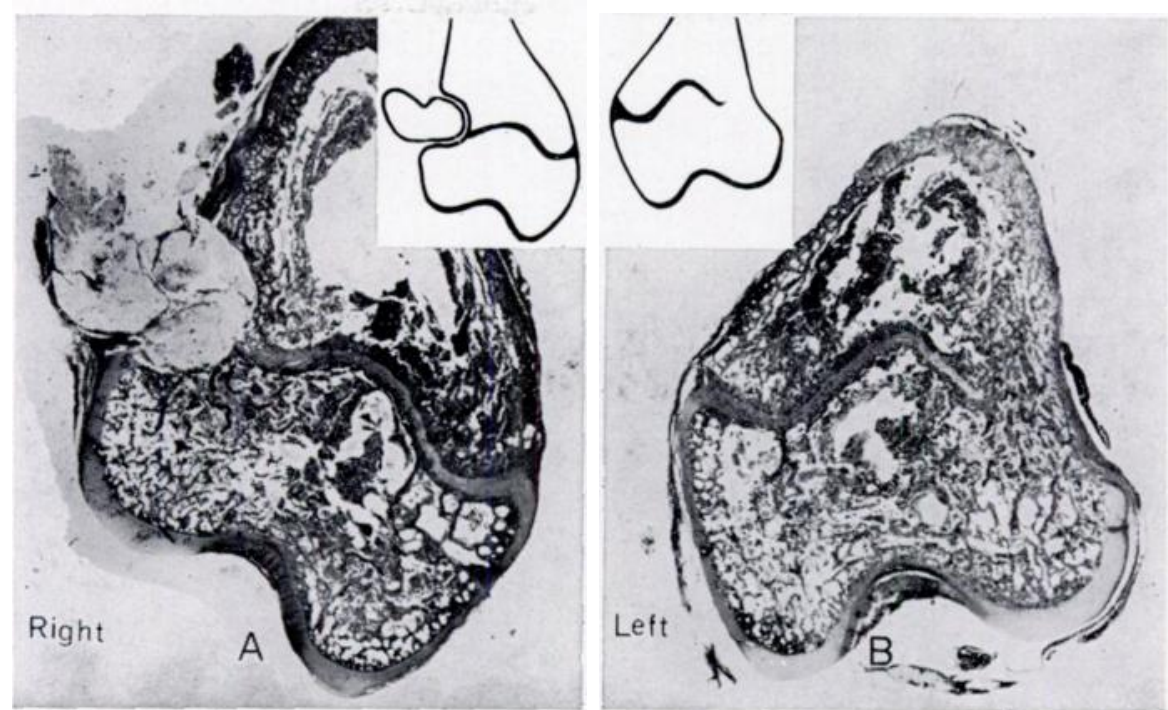

Fig. 14

Histological sections of the distal ends of the femora of a rabbit in which lateral bony bridges between epiphysis and metaphysis had been induced sixteen days before the animal was killed. On the right side the bone bridge was replaced with fat two days before the animal was killed; on the left side the bridge remained untouched. Note the outline drawings. (Reprinted from Österman (1972) by kind permission.)

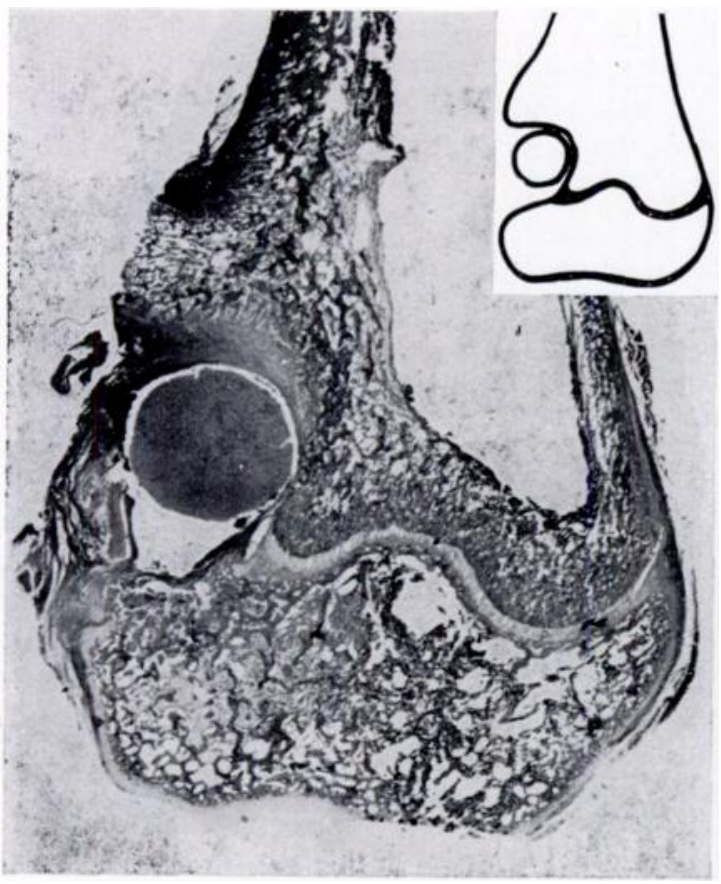

Fig. 15

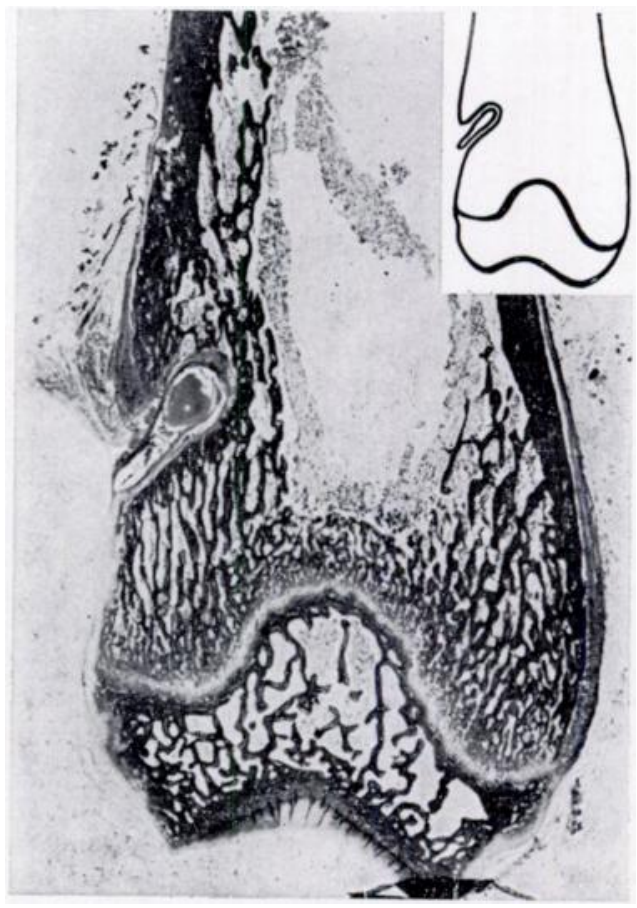

FIG. 16

Figure 15-A histological section of the distal end of femur of a rabbit in which a bony bridge had been present for two weeks before it was replaced with a cartilage transplant. The animal was killed fifteen days later. During this time the whole femur had grown and regeneration had started to replace the missing portion of the growth plate. (Reprinted from Osterman (1972) by kind permission.) Figure 16-A histological section of the distal end of femur of a rabbit from which a bone bridge was resected and replaced with a cartilage transplant eighty-four days previously. The plate had regenerated to its full width and the implanted cartilage had been left behind as an oblique focus in the metaphysis. (Reprinted from Osterman (1972) by kind permission.)

In experiments carried out by injuring limited portions of cartilaginous plates by high doses of $x$-rays it was shown by Langenskiöld and Edgren (1949) that these by bone. However, its presence in the metaphysis prevented the formation of a bony bridge between epiphysis and metaphysis. With regard to the continued growth 
of the unharmed portion of the plate, this occurred in a transverse direction. The injured portion was pushed aside and left as an oblique focus in the peripheral part of the metaphysis (Langenskiöld 1967a). This process has later been elucidated by other methods (Langenskiöld, Rytömaa and Videman 1967).

The phenomenon that a dead portion of growth plate prevents the formation of a bony bridge was also demonstrated by Heikel (1960) in experiments on transplantation of the head of the fibula in rabbits. Moreover, Heikel showed that dead portions of epiphysial cartilage are replaced by regeneration from adjacent parts of the plate.

In a search for an interposition material to prevent scar formation in operations for scoliosis it was noted that free transplants of autogenous fat were suitable for this purpose (Langenskiöld and Michelsson 1960). The work of Lexer (1924) had already given an impulse to the use of free grafts of fat for the prevention of scar formation in connection with various other orthopaedic operations.

After the first case reported in 1967 it seemed reasonable to establish a more solid experimental basis for the operative treatment of partial closure of a plate before adopting it for routine clinical use. The experimental work published by Österman (1972) showed that when a bone bridge is resected and replaced with a free transplant of cartilage or fat, the fate of the transplant is similar to that of a portion of epiphysial cartilage injured by irradiation. The transplant prevents reformation of the bridge and is pushed aside, the epiphysial plate regaining its normal width by regeneration from the inner part of the plate toward the periphery during continued growth (Figs. 14 to 16). Moreover the experiments showed that angula- tion of the lower femur is usually gradually corrected by growth after elimination of the bridge.

In forty-six out of fifty-two experiments Österman found that reformation of a resected bone bridge was prevented by replacement with autogenous fat, and by replacement with dead homologous cartilage in twentyeight out of twenty-nine experiments. Bone wax was also found effective as an interposition material. It was later found by Bright (1974) that reformation of a bridge may be prevented by the interposition of Medical Silastic No. 382.

\section{DISCUSSION}

The clinical cases described above prove that the possibility of effective treatment of partial closure of an epiphysial plate advanced by the author in 1967 is a reality. These cases mark the first steps into a new field of surgery to promote normal growth of damaged epiphysial plates. Despite a firm experimental basis for the use of the operation in cases with a small peripheral bone bridge, several matters are still under consideration. Certainly the operation should not be performed at an age when too little growth is left to allow correction of deformity or some gain in bone length, but the age limits cannot yet be defined. It is not yet clear how large a bridge may be resected with an acceptable clinical result. A major loss of cartilage from trauma or disease probably means that closure of the entire plate will be premature even if the bridge has been entirely removed. Variations in the size and situation of a bone bridge causing growth disturbance and vascular problems certainly affect the indications for and the results of the operation. These questions may be at least partly answered by further experimental work on animals.

\section{REFERENCES}

Bright, R. W. (1974) Operative correction of partial epiphyseal plate closure by osseous-bridge resection and silicone-rubber implant. Journal of Bone and Joint Surgery, 56-A, 655-664.

Heikel, H. V. A. (1960) Experimental epiphyseal transplantation. Part II. Histological observations. Acta orthopaedica Scandinavica, 30, $1-19$.

Langenskiöld, A. (1947) Normal and pathological bone growth in the light of the development of cartilaginous foci in chondrodysplasia. Acta chirurgica Scandinavica, 95, 367-386.

Langenskiöld, A. (1967a) The stages of development of the cartilaginous foci in dyschondroplasia (Ollier's disease). Acta orthopaedica Scandinavica, 38, $174-180$.

Langenskiöld, A. (1967b) The possibilities of eliminating premature partial closure of an epiphyseal plate caused by trauma or disease. Acta orthopaedica Scandinavica, 38, 267-279.

Langenskiöld, A., and Edgren, W. (1949) Imitation of chondrodysplasia by localized roentgen ray injury-an experimental study of bone growth. Acta chirurgica Scandinavica, 99, 353-373.

Langenskiöld, A., and Michelsson, J.-E. (1960) Unpublished observations.

Langenskiöld, A., Rytömaa, T., and Videman, T. (1967) An autoradiographic study with ${ }^{36}$ S-sulphate on the growth in diameter of epiphyseal cartilage in rabbits. Acta orthopaedica Scandinavica, suppl. No. 106.

Lexer, E. (1924) Die freien Transplantationen. 1. Teil. Neue Deutsche Chirurgie, 26a. Stuttgart: F. Enke.

Salter, R. B., and Harris, W. R. (1963) Injuries involving the epiphyseal plate. Journal of Bone and Joint Surgery, 45-A, 587-622.

Osterman, K. (1972) Operative elimination of partial premature epiphyseal closure. An experimental study. Acta orthopaedica Scandinavica, suppl. No. 147. 